\title{
Neuropsychological Profile, Cognitive Reserve and Emotional Distress in a Portuguese Sample of Severely Obese Patients
}

\author{
Perfil Neuropsicológico, Reserva Cognitiva e \\ Desajustamento Emocional numa Amostra Portuguesa \\ de Doentes com Obesidade Grave
}

\author{
Olga RIBEIRO $\triangle^{1,2}$, Isabel do CARMO $^{3}$, Teresa PAIVA ${ }^{4}$, Maria Luísa FIGUEIRA ${ }^{5}$ \\ Acta Med Port 2020 Jan;33(1):38-48 - https://doi.org/10.20344/amp.12233
}

\section{ABSTRACT}

Introduction: Obesity is a significant risk factor for multiple comorbidities, and its relation to neurocognitive disfunction is particularly important in cognitive decline, especially in middle age. Due to their impact on neurodegeneration, we sought to explore neuropsychological profile, cognitive reserve and emotional distress in patients with severe obesity.

Material and Methods: We used a sociodemographic and clinical questionnaire, neuropsychological tests and a symptom self-reported scale of emotional distress. We evaluated the cognitive performance of 120 patients, aged between 18 and 65 years, in treatment for their severe obesity in Portugal, between May 2012 and December 2015.

Results: Cognitive performance was below the mean for the Portuguese population, for immediate recall, visuoperception, resistance to interference and cognitive flexibility. Cognitive reserve was mostly low, especially in the older groups and groups with low professional status and increased associated with better cognitive outcomes. Emotional distress was shown to be higher in our sample compared with a normative sample. The risk factors evaluated were important in the worsening of cognitive functions. Cognitive performance decreased with age.

Discussion: Severe obesity was associated with a poorer cognitive performance of the sample. The cognitive reserve was greater in the younger groups. There was a significant presence of emotional distress, especially among women.

Conclusion: Severe obesity is associated with an impairment in cognitive and emotional performance, aggravated by aging, cognitive reserve, and comorbidity. This study emphasizes the need for preventive actions, such as neuropsychological screening, in the detection of changes and the design of better interventions.

Keywords: Emotions; Executive Function; Cognition; Cognitive Reserve; Obesity, Morbid/psychology; Portugal

\section{RESUMO}

Introdução: A obesidade é fator de risco significativo para múltiplas comorbilidades e a sua relação com a disfunção neurocognitiva é de particular importância no declínio cognitivo particularmente na meia-idade. Explorámos o perfil neuropsicológico, a reserva cognitiva e o desajustamento emocional, em doentes com obesidade grave, devido ao seu impacto na neuro-degeneração.

Material e Métodos: Questionário sociodemográfico e clínico, provas neuropsicológicas e de avaliação de sintomas de desajustamento emocional, na avaliação do desempenho cognitivo de 120 doentes, entre os 18 e os 65 anos, em tratamento da sua obesidade grave em Portugal, entre maio de 2012 e dezembro de 2015.

Resultados: O desempenho cognitivo situou-se abaixo do valor médio da população portuguesa, para a memória imediata, visuoperceção, resistência à interferência e flexibilidade cognitiva. A reserva cognitiva foi maioritariamente baixa, principalmente nos grupos de pacientes com mais idade e com status profissional mais baixo. A sua elevação associou-se a melhores resultados cognitivos. $O$ desajustamento emocional denotou significativa elevação comparativamente com uma amostra normativa. Os fatores de risco avaliados foram importantes no agravamento das funções cognitivas e o desempenho cognitivo decresceu com o aumento da idade.

Discussão: A obesidade grave esteve associada a um pior desempenho cognitivo da amostra. A reserva cognitiva foi superior nos mais jovens. Houve presença expressiva de mal-estar emocional particularmente entre as mulheres.

Conclusão: A obesidade grave está associada a uma diminuição do desempenho cognitivo e emocional que é coadjuvada pelo enveIhecimento, reserva cognitiva baixa e comorbilidade. Sublinha-se, neste trabalho, a necessidade de ações preventivas entre as quais o screening neuropsicológico na deteção de alterações e conceção de melhores intervenções.

Palavras-chave: Cognição; Emoções; Funções Executivas; Obesidade Mórbida/psicologia; Portugal; Reserva Cognitiva

\section{INTRODUCTION}

In Portugal, as is true in several regions of the world, obesity is a chronic condition and a risk factor for multiple diseases among various age groups, constituting a strong concern for public health. ${ }^{1}$ The increase in the prevalence

of this condition has led researchers to consider genetic, environmental, social, behavioural and individual psychological characteristics as fundamental factors acting both in the onset and maintenance of obesity. ${ }^{2}$

1. Unidade de Neuropsicologia. Hospital de Egas Moniz. Lisboa. Portugal.

2. ISAMB - Instituto de Saúde Ambiental. Lisboa. Portugal.

3. Departamento de Endocrinologia, Diabetes e Metabolismo. Hospital de Santa Maria. Lisboa. Portugal.

4. CENC - Centro de Medicina do Sono. Lisboa. Portugal.

5. Departamento de Psiquiatria. Hospital de Santa Maria. Lisboa. Portugal.

$\triangle$ Autor correspondente: Olga Ribeiro. olgaribei@gmail.com

Recebido: 21 de abril de 2019 - Aceite: 24 de julho de 2019 | Copyright @ Ordem dos Médicos 2020 
Obesity is usually associated with diseases with an equally chronic profile such as arterial hypertension (HTN), type 2 diabetes (DM), dyslipidaemia, obstructive sleep apnoea syndrome (OSAS), and depressive syndrome. Such diseases worsen with extreme obesity [body mass index $\left.(B M I) \geq 40 \mathrm{~kg} / \mathrm{m}^{2}\right]$ and are associated with further impairment in quality of life and prognosis. ${ }^{3}$

Several epidemiological studies have highlighted the deleterious effect of obesity, impaired fasting glucose, dyslipidaemia and hypertension on cognition. They suggest that metabolic syndrome may be a prodromal state of vascular cognitive impairment. ${ }^{4}$ Regarding diabetes, a link to different stages of cognitive disfunction has been described, ranging from diabetes-associated decrements to dementia. ${ }^{5}$ According to authors, these stages are not necessarily part of a continuous process and may show different prognoses.

The relationship between obesity and cognitive functioning, particularly during middle age, is also well-documented. It has been characterized as a significant risk factor for the appearance of cognitive decline and vascular dementia or Alzheimer's disease (AD), regardless of comorbid diseases. ${ }^{6}$ Elderly patients with severe obesity displayed higher concentrations of hippocampal markers associated with $A D$ (amyloid $B$ and tau) than those who were not obese. ${ }^{7,8}$

Neuroimaging studies have identified structural changes, morphometric differences, and changes in regional cerebral perfusion, especially in the frontal, temporal, and parietal regions and in a manner inversely associated with BMI. These alterations suggest obesity play a role in the appearance of dementia processes at different life stages. ${ }^{9}$ Cognitive neuroscience recognizes the importance of cerebral regions like the prefrontal cortex, especially the dorsolateral and orbitofrontal areas, as critical locations of cognitive control and executive functioning that play an essential role in the processes of learning and memory. ${ }^{2}$ This cerebral area participates in the food self-regulation process together with mesolimbic cortical structures, which are responsible for reward centres and for the strong hedonic component of food choice. The decrease in the volume of these areas may, therefore, lead to less cognitive control, with implications for inhibitory control, regulation of affection and motivation, and a greater propensity for opportunistic ingestion with enhanced pleasure from high palatability foods.

One of the potential moderators of the association between BMI and cognitive performance is cognitive reserve (CR), a dynamic model that relies on a set of protective/ moderating factors that enable the maintenance of effective cognitive performance abilities or delay the manifestation of their decline in cerebral pathology or normal ageing. ${ }^{10-12}$ Most researchers consider that $\mathrm{CR}$ is influenced by multiple factors such as schooling, professional performance, and leisure activities. ${ }^{13} \mathrm{~A}$ high CR positively influences cognitive performance in patients with obesity ${ }^{14,15}$ as well as in those with traumatic brain injury, ${ }^{16}$ multiple sclerosis, ${ }^{17,18}$ or bipolar disorder. ${ }^{19}$ Its determination in obesity, in particular, can be an important measure in predicting better cognitive health, better adaptation to change, and the acquisition of new life habits.

For cognitive performance, affective states, such as anxiety and depression, can also contribute to 'executive dysfunction'. ${ }^{20}$ Emotional processing in the presence of such states of being is associated with structural and functional changes in the prefrontal cortex, leading to poor mental performance, particularly with respect to cognitive flexibility and inhibitory control. ${ }^{21}$ These are functions that, among many, promote the rigidity of behaviours equally facilitated by advancing age. Anxiety and depression are also highly prevalent in obesity with recent clinical findings suggesting the possibility of shared pathophysiological pathways between these conditions and their influence on memory performance across a lifespan. ${ }^{22,23}$

It is recognized that, with ageing-related cardiovascular diseases, the precursors of dementia increase, and it is necessary to identify early risk factors among which obesity has one of the highest prevalence rates in Europe. ${ }^{24}$ It is therefore urgent to focus on prevention by changing behaviours and promoting healthy living habits in younger populations, ensuring a slower path of age-related cognitive decline and identifying appropriate therapeutic interventions in situations where the disease is already present. ${ }^{25}$ In the latter case, it is necessary to improve the susceptibility to distraction by food cues and the regulation of food intake and reward, characteristics consistently linked to reduced attention and memory functions in obese patients. ${ }^{26,27}$ It is also critical to promote the adaptation, flexibility, emotional regulation, and regulation of the self-control mechanism of obese patients, which are characteristics inherent to the executive functions. These are functions that need to be activated whenever we emit a behaviour directed towards a given objective that influence stages from planning to execution. ${ }^{28}$ They have been described in the obese population as impoverished in the field of decision-making, control of impulsivity, and emotional regulation of depression and anxiety. ${ }^{20}$

Our study aimed to describe and explore the neuropsychological profile, the $\mathrm{CR}$, and the indicators of emotional distress of a sample of patients with severe obesity seen at a Portuguese referral centre for the treatment of obesity. We focused on attention, memory and executive functions due to their impact on general cognitive functioning and emotional control.

This goal is particularly important because (1) it emphasizes the study of cognitive functions in extreme conditions of disease such as severe obesity, (2) adds new data to the literature on the application of CR analysis in a sample aged not older than 65 years (and therefore considered not yet elderly) $)^{29}$ and (3) highlights emotional aspects that are not confined only to depressive and anxious symptoms, but instead to a greater diversity of facets of psychopathology.

The evaluation, stimulation, and rehabilitation of the referred-to functions are important for the optimization of treatment programs and the avoidance of weight gain with increasing age, since obesity may contribute to the early manifestation of certain neurodegenerative diseases. 


\section{MATERIAL AND METHODS}

After obtaining approval from the ethics committee of the Centro Hospitalar de Lisboa Norte, we evaluated 120 patients with severe obesity who sought treatment at the Morbid Obesity Consultation Centre between May 2012 and December 2015.

Patients were eligible for participation in the study, regardless of gender, if they were aged between 18 and 65 years, severely obese (BMI $\left.\geq 40 \mathrm{~kg} / \mathrm{m}^{2}\right)$, without any known diagnosis of psychiatric or neurological disorders, had at least four years of schooling, and had noncorrected hearing and vision.

\section{Materials}

A sociodemographic and clinical questionnaire to collect personal and social characteristics and relevant clinical data was administered. A paper and pencil neuropsychological

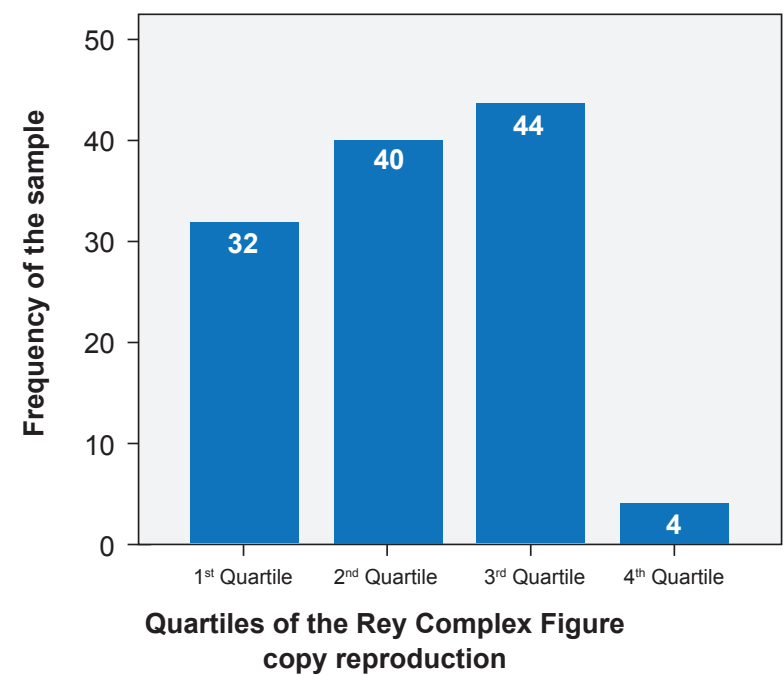

battery of evaluations was given to assess the following: attention and working memory [Wechsler Intelligence Digit Span for Adults (WAIS)-III] ${ }^{30}$; fine motor control and learning speed (digit symbol from the WAIS-III) ${ }^{31}$; processing speed (search symbol from the WAIS-III) ${ }^{30}$; level of education, culture and acquired knowledge (vocabulary from the WAIS-III) ${ }^{30}$; perceptual/visuospatial ability [Rey-Osterrieth Complex Rey Figure (RCF)] $]^{32}$ (Fig. 1); retention, consolidation, storage, and retrieval of verbal information and episodic memory [Rey Auditory Verbal Learning Test (RAVLT)] ${ }^{33}$; resistance to interference (Stroop Colour Test and Word Test) ${ }^{34}$; cognitive flexibility [Trail-making Test (TMT)] ${ }^{35}$; cognitive flexibility, abstract thinking, the ability to shift cognitive strategies in response to changing environmental contingencies as well as handle problem-solving and changing of cognitive strategy [Wisconsin Card Sorting Test (WCST)] ${ }^{36}$; the Portuguese version of the Symptom Scale of Emotional Adjustment/Maladjustment in Psychiatric/Psychological

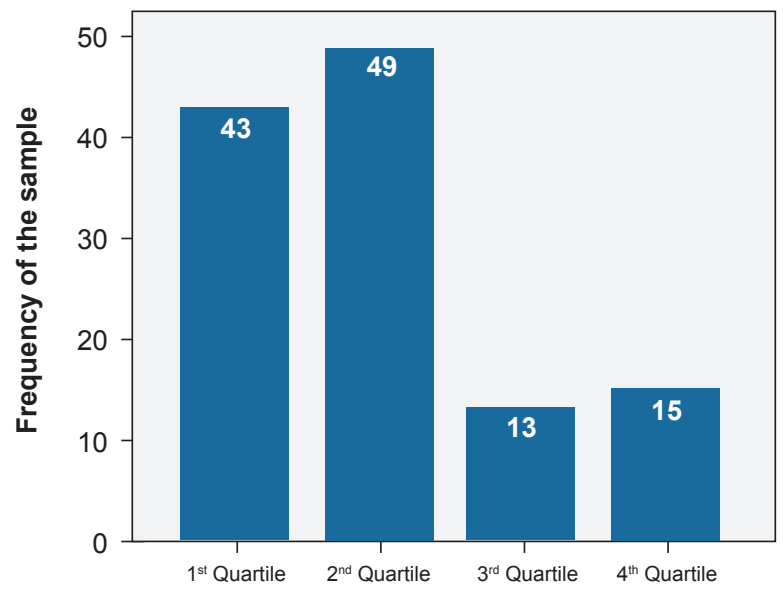

Quartiles of the Rey Complex Figure memory reproduction

Figure 1 - Distribution of the sample by quartiles of the Rey Complex Figures copy and memory reproduction $(n=120)$

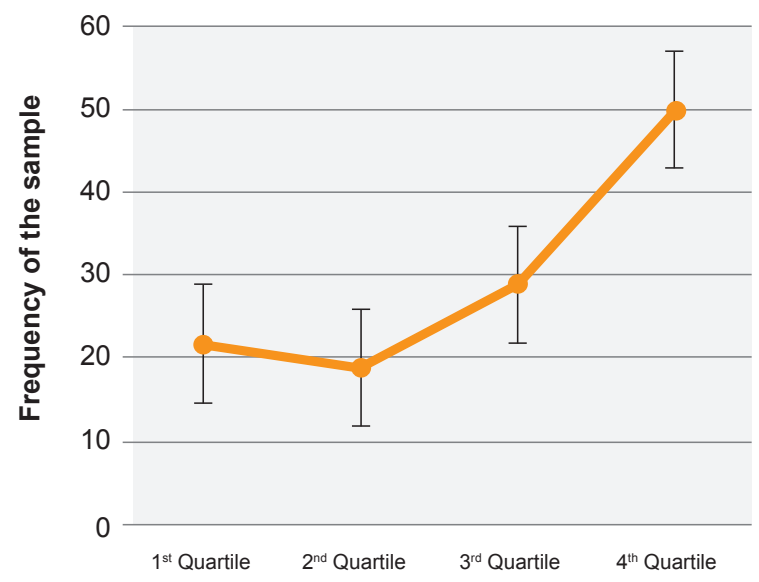

Quartiles of the Global Severy Index

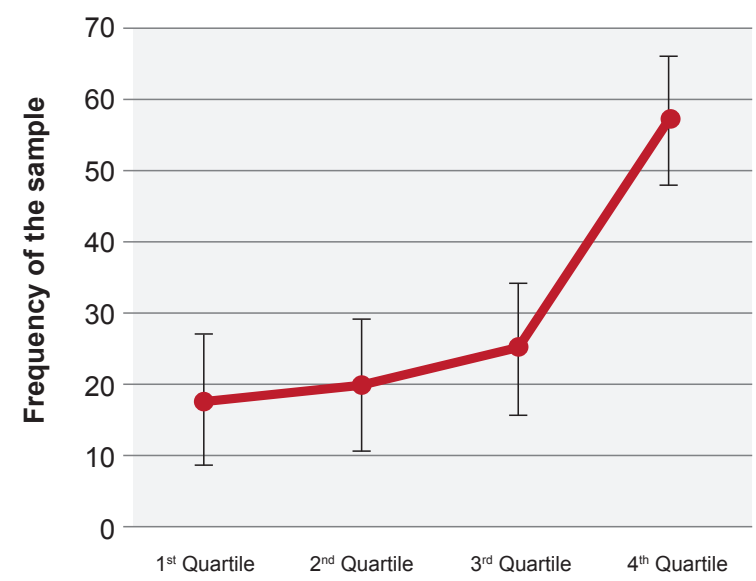

Quartiles of the Positive Symptom Distress Index

Figure 2 - Distribution of the sample by quartiles of the global severity index and positive symptom distress index of the Symptom Checklist-Revised $(n=120)$ 
Patients [Hopkins Symptom Checklist-Revised (SCL90-R)] $]^{37}$ (Fig. 2).

\section{Procedures}

At the end of their required endocrinology consultation, patients were invited to participate in the present study.

We adopted a sequential sampling sequence, assuming a non-attendance rate of the first query near $30 \%{ }^{38}$

We explained the purpose of the study to each patient, confirmed their voluntary interest, and obtained informed consent information.

We took anthropometric measurements such as weight, height, neck circumference, waist circumference, and hip circumference. Blood arterial pressure was obtained by the interviewing nurse, and was defined as HTN - MR if systolic blood pressure $>140 \mathrm{mmHg}$ and/or diastolic blood pressure $>90 \mathrm{mmHg}^{39}$

We calculated BMI as weight $(\mathrm{kg})$ divided by height $\left(\mathrm{m}^{2}\right)$. We obtained data on vascular risk factors such as arterial hypertension, DM, and dyslipidaemia from the clinical records of each patient.

For the CR measurement, we adopted the method of Roldan-Tapia, Garcia, Casanovas and León (2012) applied in a study that used the CR concept in one hundred and sixty healthy subjects and highlighted its relation to cognitive functions as relevant as executive functions, working memory, and attention. ${ }^{40}$

The variable $\mathrm{CR}$ resulted from the composite of measurements like the level of schooling, occupation, and vocabulary items of WAIS-III, ${ }^{41}$ summarized as follows: (1) professional complexity was compared to the Portuguese classification of professions ${ }^{42}$ and transformed into a dichotomous variable (1: no decision-making, 2: decision-making); (2) schooling defined as the number of years of formal school education considering the minimum mandatory schooling in Portugal at the beginning of the sample collection and stratified into 1 if schooling for less than nine years and 2 if schooling for nine or more years; (3) Vocabulary subtest fulfilling the WAIS-III standards for the Portuguese population and classifying the result for each patient as 1 if vocabulary was less than the average 10 points, and 2 if vocabulary was on par or greater than the average 10 points.

$\mathrm{CR}$ values were scored as 'high' when the median was five points or greater and 'low' when the median was less than five points. The variable was used continuously or dichotomized (high versus low).

We evaluated the SCL-90-R global internal consistency and showed it to be high (Cronbach $\alpha=0.913$ ). The items that lowered the internal consistency of the scale in case of exclusion were anxiety (0.894), obsession (0.895) and depression (0.895). The items that increased the internal consistency of the scale in case of exclusion were phobic anxiety (0.907) and paranoid ideation (0.907). Although the exclusion of these items leads to greater fidelity of the instrument, we used the same items of the original version of the scale used by Batista (1993) in his study about the genesis of panic disorder. ${ }^{37}$ We compared the mean results of the cognitive tests with the means of normalization performed for the Portuguese population $(\mu=10 ; \delta=3)$ and compared the results of each of the SCL-90-R scales with the results of the Portuguese normative sample.

We evaluated the WCST instrument internal consistency and showed it to be globally good (Cronbach $\alpha=0.710$ ) for the eleven items. The items that increased the internal consistency of the scale in case of exclusion were conceptual level responses $(0.786)$ and learning to learn (0.750). The items that lowered the internal consistency of the scale in case of exclusion were administered trails (0.526) and number of errors (0.579). We compared the results of the WCST items with the results of the Portuguese normative sample used by Almeida (2018) in his study about the psychometric characteristics of the WCST in several samples of the Portuguese population. ${ }^{43}$

The evaluation battery had an average duration of 45 minutes and was applied by a psychologist with an advanced specialization focus in neuropsychology.

\section{Statistical analysis}

Statistical analysis was performed using the Statistical Package for the Social Sciences version 24.0 for Windows software program (IBM Corp., Armonk, NY, USA). The significance level was set at $p<0.05$. Since the sample did not follow a normal distribution, we used Spearman's correlation for correlations between quantitative measures, Kendall's Tau_b for correlations between quantitative and nominal measures, and nonparametric statistics to verify the homogeneity of distribution and independence of variables by gender, age, qualifications and employment status.

\section{RESULTS \\ Characterization of the sample}

The sample included patients between 18 and 65 years of age. Their sociodemographic characteristics are shown in Table 1.

Table 2 shows that the anthropometric measurements were higher in men, except for the hip circumference.

We used the Mann-Whitney $U$ test for the analysis of the homogeneity of distribution of anthropometric, cognitive and distress measurements by gender and we found higher values for males regarding weight $(U=-4.641, p=$ $.000)$, neck circumference $(U=-6.620, p=0.000)$, waist circumference $(U=-4.661, p=0.000)$, hip circumference $(U=-1.971, p=0.049)$, and waist-to-hip ratio $(U=-6.335$, $p=0.000)$. Men also presented better results for the means distribution on RCF memory $(U=-2.149, p=0.032)$.

Women presented higher means for distress measurements namely, global severity index $(U=3.602, p=0.000)$, positive distress index $(U=3.509, p=0.000)$, somatization $(U=4.282, p=0.000)$, obsessive-compulsive $(U=2.812$, $p=0.005)$, interpersonal sensitivity $(U=3.838, p=0.000)$, depression $(U=4.034, p=0.000)$, anxiety $(U=4.474, p=$ $0.000)$, hostility $(U=2.406, p=0.016)$, phobic anxiety $(U=$ 2.062, $p=0.039)$ and psychoticism $(U=2.092, p=0.036)$.

Regarding the homogeneity of the distribution of 
Table 1 - Sociodemographic and clinical characterization of the sample $(n=120)$

\begin{tabular}{|c|c|c|}
\hline & $\mathbf{n}$ & $\%$ \\
\hline \multicolumn{3}{|l|}{ Gender } \\
\hline Female & 92 & 76.7 \\
\hline Male & 28 & 23.3 \\
\hline \multicolumn{3}{|l|}{ Age } \\
\hline $18-20$ years & 2 & 1.7 \\
\hline $21-30$ years & 25 & 20.8 \\
\hline $31-40$ years & 32 & 26.7 \\
\hline $41-50$ years & 30 & 25.0 \\
\hline $50-60$ years & 27 & 2.5 \\
\hline$>60$ years & 4 & 3.3 \\
\hline \multicolumn{3}{|l|}{ Marital status } \\
\hline Singles & 21 & 17.5 \\
\hline Married/unmarried couples & 84 & 70.0 \\
\hline Separate/divorced & 15 & 12.5 \\
\hline \multicolumn{3}{|l|}{ Employment Status } \\
\hline Employed & 67 & 55.8 \\
\hline Unemployed & 38 & 31.7 \\
\hline Pensioners & 11 & 9.2 \\
\hline Students & 1 & 0.8 \\
\hline Others & 3 & 2.5 \\
\hline \multicolumn{3}{|l|}{ Qualifications } \\
\hline $1^{\text {st }}$ Cycle of basic school & 20 & 16.7 \\
\hline $2^{\text {nd }}$ Cycle of basic school & 21 & 17.5 \\
\hline $3^{\text {rd }}$ Cycle of basic school & 35 & 29.2 \\
\hline Secondary school & 34 & 28.3 \\
\hline Bachelor/graduation/master & 10 & 8.3 \\
\hline \multicolumn{3}{|l|}{ Income } \\
\hline Without Income & 14 & 11.7 \\
\hline$<500$ euros & 40 & 33.3 \\
\hline $500-750$ euros & 41 & 34.2 \\
\hline $750-1000$ euros & 14 & 11.7 \\
\hline $1000-1500$ euros & 9 & 7.5 \\
\hline$>1500$ euros & 2 & 1.7 \\
\hline \multicolumn{3}{|l|}{ Clinical diagnosis } \\
\hline Arterial hypertension & 67 & 55.8 \\
\hline Type 2 diabetes & 22 & 18.3 \\
\hline Dyslipidaemia & 34 & 28.3 \\
\hline \multicolumn{3}{|l|}{ Lifestyle habits } \\
\hline Tobacco consumption & 30 & 25 \\
\hline Alcoholic beverages consumption & 29 & 24.2 \\
\hline Regular physical activity & 27 & 22.5 \\
\hline \multicolumn{3}{|l|}{ Obesity Course } \\
\hline Overweight since childhood & 55 & 45.8 \\
\hline With at least two attempts at weight loss & 20 & 16.7 \\
\hline Expert-oriented weight loss trials & 104 & 86.7 \\
\hline Assignment of weight to wrong daily habits & 62 & 51.7 \\
\hline
\end{tabular}

anthropometric, cognitive and distress measurements by age groups, schooling and professional status, we used the Kruskal-Wallis test and we obtained differences for means of neck circumference $(K-W=9.514, p=0.049)$, waistto-height ratio $(K-W=11.211, p=0.024)$ and $\mathrm{BMI}(K-W=$ $13.453, p=0.009$ ) only for professional status, with the unemployed group of patients showing higher values.

Considering age groups we found mean differences for immediate recall $(K-W=18.034, p=0.003)$, digit symbol $(K-W=27.260, p=0.000)$, search symbol $(K-W=36.226$, $p=0.000)$, TMTA $(K-W=18.000, p=0.003)$, TMT B $(K-W$ $=21.268, p=0.001)$, RCF memory $(K-W=28.883, p=$ $0.000)$, WCST conceptual level responses $(K-W=12.165$, $p=0.033)$, WCST number of completed categories $(K-W=$ $12.787, p=0.025)$ with the oldest groups $(51-60$ years old and $>60$ years old) presenting worse results.

Our results pointed to a difference in the distribution of cognitive measurements by schooling with the most qualified groups presenting the best values for immediate recall $(K-W=30.454, p=0.000)$, digit symbol $(K-W=50.569, p$ $=0.000)$, search symbol $(K-W=42.620, p=0.000)$, digit $\operatorname{span}(K-W=24.174, p=0.000)$, TMT A $(K-W=35.639, p=$ $0.000)$, TMT B $(K-W=44.539, p=0.000)$, RCF copy $(K-W$ $=13.162, p=0.041)$, RCF memory $(K-W=13.616, p=$ $0.034)$, WCST number of administered trials $(K-W=20.100$, $p=0.003)$, WCST number of errors $(K-W=21.946, p=$ $0.001)$, WCST number of perseverative responses $(K-W=$ 21.972, $p=0.001$ ), WCST number of perseverative errors $(K-W=21.341, p=0.002)$, WCST number of conceptual level responses $(K-W=16.656, p=0.011)$ and WCST number of completed categories $(K-W=18.873, p=0.004)$.

Regarding professional status, we obtained a difference of means with the employed patients showing better values for deferred recognition $(K-W=12.010, p=0.017)$, digit symbol $(K-W=11.063, p=0.026)$, search symbol $(K-W=$ $15.363, p=0.004)$, TMT A $(K-W=10.482, p=0.033)$, TMT $\mathrm{B}(K-W=15.256, p=0.004)$, RCF memory $(K-W=16.614$, $p=0.002)$, WCST number of administered trials $(K-W=$ $15.810, p=0.003)$, WCST number of errors $(K-W=16.634$, $p=0.002)$, WCST number of perseverative responses $(K-W$ $=13.610, p=0.009)$, WCST number of perseverative errors $(K-W=15.812, p=0.003)$, WCST number of non-perseverative errors $(K-W=27.260, p=0.000)$, WCST number of conceptual level responses $(K-W=14.004, p=0.007)$, WCST number of completed categories $(K-W=21.627, p$ $=0.000)$, and WCST learning to learn $(K-W=12.308, p=$ 0.015).

The positive distress Index $(K-W=9.748, p=0.045)$ and the depression mean values $(K-W=11.776, p=0.019)$ had the best values in the employed groups.

Weight was the only anthropometric measurement to correlate negatively with age $(r=-0.219, p=0.016)$.

Regarding the CR (high versus low), $46.7 \%$ of the patients $(n=56)$ had a high CR and $53.3 \%$ of the sample $(n=$ 64) had a low CR.

The groups aged $41-50$ years old $(32.8 \%$ with low CR vs $16.1 \%$ with high $\mathrm{CR})$ and 51 - 60 years old $(28.1 \%$ with low 
Table 2 - Descriptive statistic of the anthropometric measurements of the sample $(n=120)$

\begin{tabular}{lccccc}
\hline & Min & Max & $\begin{array}{c}\text { Mean and standard } \\
\text { deviation of } \\
\text { the total sample }\end{array}$ & $\begin{array}{c}\text { Mean and standard } \\
\text { deviation of } \\
\text { of women }\end{array}$ & $\begin{array}{c}\text { Mean and standard } \\
\text { deviation } \\
\text { of men }\end{array}$ \\
& & & $\mathbf{n}=120$ & $\mathbf{n}=92$ & $\mathbf{n}=28$ \\
\hline Weight $(\mathrm{kg})$ & 90 & 172.30 & $127.08( \pm 18.72)$ & $122.61( \pm 17.03)$ & $141.78( \pm 16.55)$ \\
Height $(\mathrm{cm})$ & 148 & 194.00 & $164.81( \pm 9.58)$ & $161.61( \pm 6.87)$ & $175.32( \pm 9.82)$ \\
Neck circumference $(\mathrm{cm})$ & 35 & 68.00 & $43.34( \pm 4.72)$ & $41.97( \pm 4.37)$ & $47.85( \pm 2.46)$ \\
Waist circumference $(\mathrm{cm})$ & 93 & $>150.0$ & $130.35( \pm 13.94)$ & $127.14( \pm 13.34)$ & $140.92( \pm 10.30)$ \\
Hip circumference $(\mathrm{cm})$ & 114 & $>150.0$ & $137.99( \pm 10.01)$ & $139.07( \pm 9.61)$ & $134.42( \pm 10.66)$ \\
Hip waist ratio & 0.68 & 1.23 & $0.94( \pm 0.09)$ & $0.91( \pm 0.076)$ & $1.05( \pm 0.086)$ \\
Waist height ratio & 0.59 & 0.99 & $0.79( \pm 0.08)$ & $0.78( \pm 0.089)$ & $0.80( \pm 0.066)$ \\
BMI & 40 & 63.29 & $46.72( \pm 5.54)$ & $46.95( \pm 5.94)$ & $46.08( \pm 3.95)$ \\
\hline
\end{tabular}

CR vs $16.1 \%$ with high CR) had the most patients with the lowest CR. Conversely, the highest CR was found among the younger age groups of $21-30$ years old $(14.1 \%$ with low CR vs $28.6 \%$ with high CR) and 31 - 40 years old $(20.3 \%$ with low $\mathrm{CR}$ vs $33.9 \%$ with high $\mathrm{CR}$ ).

We did not find homogeneity in the distribution of CR by age groups $(U=-2.627, p=0.009)$ and by professional status $(U=-2.114, p=0.035)$. Age was higher in the low $C R$ group.

The correlation between the CR (continuous variable) sociodemographic variables, and anthropometric and cognitive measurements are displayed in Table 3.

Schooling decreased with age (Tau_b Kendall $=-0.334$, $p=0.000)$.

The cognitive performance for learning $(\mu=9.94 ; \delta=$ 2.32), digit symbol $(\mu=10.29 ; \delta=3.20)$, search symbol $(\mu$ $=11.21 ; \delta=2.68)$ and TMT A $(\mu=9.79$ and $\delta=2.57)$ was within the standard deviation, considering the scalar mean values for the Portuguese population $(\mu=10.0 ; \delta=3)$.

Immediate recall $(\mu=8.41 ; \delta=2.33)$, retention index $(\mu$ $=9.69 ; \delta=2.86)$, digit span $(\mu=10.63 ; \delta=3.67)$ and TMT $\mathrm{B}(\mu=9.42 ; \delta=2.78)$ presented results 0.5 below standard deviation regarding the Portuguese population.

The results for the mean percentile of the Stroop interference $(\mu=45.86$; $\delta=8.56)$ were below the Portuguese norms $(\mu=50$ and $\delta=10)$, with $71.6 \%(n=86)$ of the patients in the first and second quartile. Stroop interference was significant and negatively correlated with BMI $(r=$ $-0.161, p=0.011)$.

For the RCF, 60\% ( $n=72$ ) of the patients were in the first and second quartiles for the copy and $76.7 \%(n=92)$ were in the first and second quartiles in the memory reproduction. Results of the mean values of the reproduced units of the RCF copy and memory were respectively: $\mu=44.38$; $\delta=25.35$ and $\mu=38.41$ and $\delta=26.41$.

Regarding WCST, from the total of patients, $24.2 \%$ ( $n$ $=29$ ) had no results in learning to learn which led us to exclude this item from our comparisons. The older groups presented lower percentage of conceptual level responses $(K-W=12.165, p=0.033)$ and completed categories $(K-W$ $=12.787, p=0.025)$. The more educated patients showed lower percentage of administered trials $(K-W=18.608, p$ $=0.005)$, errors $(K-W=21.946, p=0.001)$, perseverative responses $(K-W=21.972, p=0.001)$, perseverative errors $(K-W=21.341, p=0.002)$, conceptual level responses $(K-W=16.656, p=0.011)$ and greater completed categories $(K-W=18.873, p=0.004)$. When we compared our mean results with the mean results of Almeida $(2018)^{43}$ for an adult population with normal weight $(n=223)$, our patients revealed lower percentage of correct responses (53.09 vs 77.8) and conceptual level responses (43.18 vs 63.8). Our mean value for the completed categories was $4.14( \pm 1,88)$, quite below the mean referred in the Brazilian manual ${ }^{36}$ for adult populations $[5.24( \pm 0.54)$ a $5.81( \pm 1.35)]$. BMI was correlated with the WCST administered trails $(r=0.157, p=$ $0.020)$, errors $(r=0.131, p=0.035)$, perseverative responses $(r=0.123, p=0.049)$, perseverative errors $(r=0.123, p=$ $0.049)$, non-perseverative errors $(r=0.174, p=0.005)$ and completed categories $(r=-0.191, p=0.005)$.

Immediate recall $(r=-0.189 p=0.039)$, retention index $(r=-0.222 p=0.015)$, deferred recognition $(r=-0.218, p=$ $0.017)$, somatization $(r=-0.226, p=0.013)$, and anxiety $(r$ $=-0.215, p=0.019$ ) were correlated with the waist-to-hip ratio. Immediate recall $(r=-0.189 p=0.039)$ and deferred recognition $(r=-0.219, p=0.016)$ were correlated with neck circumference.

Hip circumference was the only anthropometric measurement positively correlated with global severity index $(r$ $=0.221, p=0.015)$, somatization $(r=0.185, p=0.043)$, obsession-compulsion ( $r=0.217, p=0.017$ ), interpersonal sensitivity $(r=0.269, p=0.03)$, depression $(r=0.279, p=$ $0.002)$, anxiety $(r=0.277, p=0.002)$ and phobic anxiety $(r$ $=0.265, p=0.003)$. Depression $(r=-0.223, p=0.012)$ was negatively correlated with memory reproduction in the RCF as well as anxiety ( $r=-0.186, p=0.042)$.

We compared the symptomatologic mean values obtained in the different scales of SCL-90-R with the values obtained by Batista (1993) in his adaptation of SCL-90-R applied to a normative population of 302 subjects. This comparison is expressed in Table $4 .{ }^{37}$ Of the total group, $41.7 \%(n=50)$ of the patients presented values that were within the fourth quartile for the global severity index and 
Table 3 - Significant non-parametric correlations (Spearmen and Tau_b Kendall) between sociodemographic, anthropometric and cognitive measurements, and cognitive reserve, HTN, diabetes and dyslipidemia $(n=120)$

\begin{tabular}{|c|c|c|c|c|}
\hline Variables & Cognitive Reserve & HTN & Diabetes & Dyslipidemia \\
\hline \multicolumn{5}{|l|}{ Sociodemographic } \\
\hline Age & $-0.249^{* *}$ & $0.395^{\star *}$ & $0.271^{* *}$ & $0.255^{\star *}$ \\
\hline Professional status & $-0.310^{* *}$ & & & \\
\hline Income & $0.306^{* *}$ & & & \\
\hline \multicolumn{5}{|l|}{ Anthropometric measurements } \\
\hline Neck circumference & $-0.195^{*}$ & $0.284^{* *}$ & $0.232^{* *}$ & \\
\hline Waist circumference & & $0.158^{*}$ & & \\
\hline Waist height ratio & $-0.183^{*}$ & $0.180^{*}$ & $0.230^{* *}$ & \\
\hline BMI & & $0.191^{*}$ & & \\
\hline \multicolumn{5}{|l|}{ Cognitive measurements } \\
\hline Immediate recall & $0.355^{* *}$ & & $-0.0235^{\star *}$ & \\
\hline Deferred recognition & $0.239^{* *}$ & $-0.206^{*}$ & & \\
\hline Digit symbol & $0.562^{* *}$ & & & \\
\hline Search symbol & $0.462^{* *}$ & $-0.235^{\star *}$ & & $-0.216^{\star *}$ \\
\hline Digit span & $0.413^{* *}$ & & & \\
\hline Interference & & $-0.179^{*}$ & & \\
\hline TMT A (time) & $-0.457^{* *}$ & & & $0.175^{*}$ \\
\hline TMT B (time) & $-0.541^{* *}$ & & & \\
\hline FCR copy & $0.263^{* *}$ & & & \\
\hline RCF memory & & $-0.154^{*}$ & & $-0.154^{*}$ \\
\hline WCST nr. administered trails & $-0.385^{\star \star}$ & & & \\
\hline WCST nr. errors & $-0.347^{* *}$ & & & $0.154^{*}$ \\
\hline WCST nr. perseverative responses & $-0.381^{* *}$ & & & \\
\hline WCST nr. perseverative errors & $-0.371^{* *}$ & & & \\
\hline WCST nr. non perseverative errors & $-0.218^{*}$ & $0.194^{*}$ & & \\
\hline WCST nr. conceptual level resp & $0.192^{*}$ & & & \\
\hline WCST nr. completed categories & $0.302^{* *}$ & $-0.176^{*}$ & & $-0.165^{*}$ \\
\hline WCST nr. trail complete first category & & & & $0.163^{*}$ \\
\hline WCST learning to learn & & $-0.228^{*}$ & & $-0.293^{* *}$ \\
\hline \multicolumn{5}{|l|}{ Risk Factors } \\
\hline HTN & $-0.209^{*}$ & & & \\
\hline \multicolumn{5}{|l|}{ Diabetes } \\
\hline Dyslipidemia & $-0.257^{* *}$ & & & \\
\hline
\end{tabular}

$47.5 \%(n=75)$ were in the fourth quartile of the positive symptom distress index. In general, values were higher for women.

Risk factors were positively correlated with ageing, high anthropometric measurements and negatively correlated with cognitive performance as we describe in Table 3. Diabetes was negatively correlated only with one cognitive measurement, which was immediate recall.

\section{DISCUSSION}

The present study aimed to describe and explore the neuropsychological profile, CR, and indicators of emotional distress of a sample of patients with severe obesity who visited a Portuguese referral centre for the treatment of obesity.

Impaired results obtained for memory and executive functions but not for learning, attention or processing speed, raise the possibility that obesity differentially affects instrumental functions and specific cognitive domains with a negative impact on brain structure.

Notably, CR data emerge as an important result because more than one-half of the patients of the sample has a low CR. The highest CR was found in the younger patients, with better education, better professional status, better income, better cognitive performance, lower anthropometric measurements, and lower burden of hypertension 
Table 4 - Means and standard deviations of distress measurements of the severe obesity sample $(n=120)$ and means and standard deviations of the Portuguese normative sample $(n=302)$ used by Batista $(1993)$ in his study about the genesis of panic disorder

\begin{tabular}{lcccc}
\hline Emotional measurements & \multicolumn{2}{c}{ Gender } \\
\hline & $\begin{array}{c}\text { Obese men } \\
(\text { mean } \pm \text { SD) }\end{array}$ & $\begin{array}{c}\text { Normative men } \\
\text { (mean } \pm \text { SD) }\end{array}$ & $\begin{array}{c}\text { Obese women } \\
\text { (mean } \pm \text { SD) }\end{array}$ & $\begin{array}{c}\text { Normative women } \\
\text { (mean } \pm \text { SD) }\end{array}$ \\
\hline Global severity index & $\mu=0.69 \pm 0.43$ & $\mu=0.66 \pm 0.40$ & $\mu=1.12 \pm 0.55$ & $\mu=0.87 \pm 0.50$ \\
Positive symptom distress index & $\mu=1.46 \pm 0.34$ & $\mu=1.42 \pm 0.27$ & $\mu=1.79 \pm 0.43$ & $\mu=1.54 \pm 0.38$ \\
Somatization & $\mu=0.75 \pm 0.51$ & $\mu=0.55 \pm 0.48$ & $\mu=1.40 \pm 0.72$ & $\mu=0.85 \pm 0.58$ \\
Obsessive-compulsive & $\mu=0.94 \pm 0.42$ & $\mu=0.98 \pm 0.53$ & $\mu=1.37 \pm 0.70$ & $\mu=1.12 \pm 0.62$ \\
Interpersonal sensitivity & $\mu=0.67 \pm 0.64$ & $\mu=0.73 \pm 0.54$ & $\mu=1.32 \pm 0.82$ & $\mu=0.95 \pm 0.63$ \\
Depression & $\mu=0.75 \pm 0.51$ & $\mu=0.65 \pm 0.45$ & $\mu=1.37 \pm 0.71$ & $\mu=0.99 \pm 0.64$ \\
Anxiety & $\mu=0.44 \pm 0.45$ & $\mu=0.67 \pm 0.48$ & $\mu=0.96 \pm 0.65$ & $\mu=0.89 \pm 0.59$ \\
Hostility & $\mu=0.61 \pm 0.66$ & $\mu=0.79 \pm 0.60$ & $\mu=0.94 \pm 0.71$ & $\mu=0.86 \pm 0.64$ \\
Phobic anxiety & $\mu=0.30 \pm 0.40$ & $\mu=0.29 \pm 0.38$ & $\mu=0.55 \pm 0.62$ & $\mu=0.48 \pm 0.53$ \\
Paranoid ideation & $\mu=0.80 \pm 0.71$ & $\mu=0.94 \pm 0.56$ & $\mu=1.03 \pm 0.63$ & $\mu=1.02 \pm 0.68$ \\
Psychoticism & $\mu=0.41 \pm 0.51$ & $\mu=0.40 \pm 0.42$ & $\mu=0.61 \pm 0.51$ & $\mu=0.51 \pm 0.49$ \\
\hline
\end{tabular}

SD: standard deviation

and dyslipidaemia. Together with other studies that set out to investigate age, cognitive performance, and BMI, our results reinforce the potential protective role of $C R$ in cognitive functions. ${ }^{10,15,44} \mathrm{CR}$ seems to attenuate the expression of obesity-related deficits not only on executive functions but also on memory functions.

Risk factors were shown to be highly associated with significant sociodemographic, anthropometric, and cognitive variables; a relation much too important to be ignored in these severely obese and admittedly sedentary patients. They are often a cause of reduced life expectancy and increased health care needs as particularly important causative factors of cardiovascular events and neurodegenerative diseases. ${ }^{45}$ Since their prevalence in the adult Portuguese population is estimated near $45 \%$ for $\mathrm{HTN},{ }^{47} 9.9 \%$ for DM, ${ }^{48}$ and $16 \%$ for dyslipidaemia, ${ }^{49}$ results stress the need for urgent focused strategies to avoid their onset early in life. ${ }^{50,51}$

Contrary to HTN and dyslipidaemia, that were strongly associated with $\mathrm{CR}$ and with diverse measurements of cognitive performance, DM showed a relation only to memory performance. We can only explain this results by the age of the sample, perhaps in agreement with the literature that points out that Mild Cognitive Impairment prodrome is quite rare in diabetic people younger than 65 years old. ${ }^{5}$

Surprisingly, we found that weight was higher in the younger than in the oldest patients, which was an expected variation. In fact, younger patients were shown to be more educated and had better memory, attention and cognitive flexibility indicators. It would be reasonable to expect correspondent better planning and organization of conducts toward better dietary habits and consequent weight reduction. Our hypothesis is that this could be a successful response to systematic health recommendations for weight loss in middle-aged patients.

In line with the regular reduction associated with ageing, the oldest patients demonstrated significantly lower values versus the younger ones, not only for executive functions but also for memory performance. ${ }^{52}$ The evaluated Episodic Memory is a unique system of memory that allows for the recall and re-experiencing of past events, extends to other memory systems, and is responsible for satiety in humans. ${ }^{53,54}$ Our analysis showed a link between its recall and recognition items and obesity when analysed by waistto-hip ratio. It represents increased body fat composition, is of high predictive value for the onset of DM and cardiovascular disease and is associated with a decrease in cognitive performance through the reduction of synaptic plasticity. ${ }^{55,56}$ In the same way, results show that we must consider neck circumference as a predictive factor for memory decline and, according to fat distribution, perhaps a prodrome in the onset of OSAS.

Regarding weight loss behavioural interventions, conceptual theory draws attention to the difficulty that obese patients have in inhibiting intrusive thoughts and suppressing automatic or dominant behaviour processes. This propensity is confirmed by the low performance in the Stroop test of our sample. ${ }^{57}$ Along with a negative relation with $\mathrm{BMI}$ and in the context of meals, it points to a tendency to opportunistically consume food in response to environmental stimuli playing an important role in the development and maintenance of obesity. ${ }^{58}$

Together with the Stroop test, WCST results suggest a dysfunctional executive profile. In this case, inhibitory control, cognitive flexibility and the adjustment of behaviours to the change of rules, are not stabilised and are worsened by increasing age, decreasing schooling and low professional status. This profile has been systematically reported and may represent a barrier to the adherence to new nutritional guidelines and a tendency to continue the previous regime, perpetuating weight gain and obesity. ${ }^{59}$

Along the same lines, our sample revealed decreased values for the visuoperceptive function, with women 
showing significantly poorer performance versus men. This dysfunction may be reflected in the access to the perceptual and sensorial memory of concepts such as portions, measures, magnitude and reading leaflets and labels, particularly necessary to maintain healthy food habits. ${ }^{57,60}$ Consequences includes poor understanding of the environment, low body awareness, and increased difficulties with body recognition and body confrontation. Inversely correlated with depressive and anxious symptoms, visuoperceptive memory impairments point to general emotional difficulties in the management of body image, particularly in obese women.

A wide range of distress symptoms correlated with hip circumference, the only anthropometric measurement greater in women, may reinforce the negative perceptions and feelings that these patients have of their bodies. Of interest is that measurements of emotional distress reveal considerable emotional discomfort, particularly among women, which may be due to greater competence in the emotional expression of their suffering, to which factors such as the degree of obesity, social class, sedentary lifestyle, or negative body image contribute. ${ }^{61-64}$ The appreciable range of psychological complaints, ranging from somatization to difficulty in interpersonal contact and depressive and anxious symptoms, is quite considerable and certainly has a strong contribution to the impoverishment of quality of life of this population.

Of importance is that our predominantly female sample is similar to the typical candidates for the treatment of severe obesity in Portugal. ${ }^{25,45}$ It is a patient population commonly observed in weight-management centres in industrialized countries. Its obesity is the result of multiple influences, particularly biological and evolutionary, associated with greater stigma and increased demand for help, very different from that for men. ${ }^{65,66}$

The decrease of anthropometric measurements in employed patients is an argument for the possible contribution of having a regular job to weight loss or maintenance and the reduction of cardiometabolic risk. This is a sample where most of the patients mentioned that they did not practice any kind of physical activity and more than half had a clinical diagnosis of hypertension. Besides, moderately active people have a lower risk of developing mental disorders than sedentary people and participation in exercise programs improves cognitive functioning. ${ }^{67}$

As to the onset of overweightness, a reference to childhood was reported by $46 \%$ of the patients as a determining factor for their appearance, which supports the description of this period as being one of great vulnerability to weight gain and its strong influence on the increase in obesity throughout life. This highlights the need for effective familybased interventions at this stage of development, an important phase of the systemic intervention, where feeding and physical activity are modelled by parents and mimicked by children. The results also evidence the number of weight loss attempts throughout life and the social impacts that weight fluctuation involves in terms of the investment of time, energy, and expectation, which cannot and should not be ignored, as they are associated with unfavourable physiological and psychological results. ${ }^{68,69}$

The importance of the present investigation results from the focus placed on an adult population in conditions of severe chronic disease with relatively high dimension, risk factors that were not based on self-report, age no more than 65 years, and encompassing fundamental cognitive functions in the diagnosis of neurodegenerative disease.

Its limitations, however, may explain the different results for cognitive measurements and the impossibility of their generalization. As compared with other studies, here we used the normalization values of the tests for the Portuguese population instead of a control group. We consider, however, that because the values used were the result of a scientific adaptation, validation, and normalization, they are representative and consider the sociodemographic characteristics of the Portuguese population. Patients with psychiatric disease were excluded, which may have biased the results because both depressive and anxious syndromes are factors of psychological morbidity that often present in the population with severe obesity. Finally, the nondifferentiation of the results obtained from normative values in attention tests, processing speed, and learning speed was also reported in several investigations. The authors warned that, although tests may be reliable, they may not be specifically designed to detect deficits in samples characterized by the absence of major medical, psychiatric and brain-injured conditions and, therefore, considered healthy. ${ }^{70,71}$

Since our study included a sample aged not older than 65 years, further studies are needed to clarify whether this cognitive decline persists in older ages since the prodrome of neurocognitive disease is rare, for instance, in younger diabetic patients.

\section{CONCLUSION}

The current study contributes to existing research on the neuropsychological profile of severely obese patients. Strengthening other outcomes, it shows a weakening in cognitive performance particularly in memory and executive functions, which is necessary for self-regulation of eating behaviour, management of body weight and successful of lifestyle interventions.

It provides meaningful evidence that ageing, low CR, and risk factors contribute to cognitive impoverishment in severely obese patient and may play an important role in the adherence to recommendations for diet, lifestyle options and preventing cognitive decline.

Interventions that address adherence and offer enrichment of self-control strategies, such as cognitive behavioural therapy, psycho-educative groups and cognitive training must focus on older, less educated and low professional status patients.

Significant additional behavioural procedures should include restrictive measures to prevent and avoid impulsivity and opportunistic consumption in response to food stimuli. Since overweightness is reported to start early in life, interventions should aim to identify environmental factors that 
can promote problem eating behaviours and to convene the collaboration of schools, food industry, advertising and families.

The use of waist-to-hip ratio and neck circumference should be considered in our current practice together with BMI. They help to define fat distribution and are important predictive values of comorbidities and their associated cognitive decline.

The expressive presence of emotional distress, not confined only to the depressive and anxious symptoms, may contribute to making the acceptance of body image difficult, particularly in women. It may reinforce maladaptive eating behaviours. This is, therefore, a preferred area for indispensable psychological intervention and prevention of psychiatric illness recognizing that obese women and men may have different presentations of psychological and cognitive risk factors.

In a context where clinical practice for assisting weight loss needs increasing effectiveness, our results reinforce the need for preventive and interventive tools in which neuropsychological screening, stimulation and rehabilitation can be included. They can be used in medical, nutritional or surgical programmes, in different ages, in those

\section{REFERENCES}

1. Direção-Geral de Saúde. A saúde dos Portugueses 2016. Lisboa: DGS. 2017. [accessed 2019 Jun 3]. Available from: https://comum.rcaap. pt/bitstream/10400.26/18278/1/A\%20Sa\%C3\%BAde\%20dos\%20 Portugueses\%202016.pdf.

2. Gluck M, Viswanath $P$, Stinson E. Obesity, appetite, and the prefrontal cortex. Curr Obes Rep. 2016;6:380-8.

3. Collins J, Meng C, Eng A. Psychological impact of severe obesity. Curr Obes Rep. 2016;5:435-40.

4. Segura B, Ángeles M, Freixenet N, Albuin C, Muniesa J, Junqué C. Mental slowness and executive dysfunctions in patients with metabolic syndrome. Neurosci Lett. 2009;462:49-53.

5. Koekkoek P, Kappelle L, van den Berg E, Rutten G, Biessels G. Cognitive function in patients with diabetes mellitus : guidance for daily care. Lancet Neurol. 2015;14:329-40.

6. Dye L, Boyle N, Champ C, Lawton C. The relationship between obesity and cognitive health and decline. Proc Nutr Soc. 2017;76:443-54.

7. Brien $P$, Hinder L, Callaghan B, Feldman E. Review neurological consequences of obesity. Lancet Neurol. 2017;16:465-77.

8. Jones N, Rebeck $G$. The synergistic effects of APOE genotype and obesity on Alzheimer's disease risk. Int J Mol Sci. 2019;20.

9. Gunstad J, Paul R, Cohen R, Tate D, Spitznagel M, Griev S., et al. Relathionship between body mass index and brain volume in healthy adults. Int J Neurosci. 2008;118:1582-93.

10. Galioto R, Alosco M, Spitznagel M, Stanek K, Gunstad J. Cognitive reserve preserves cognitive function in obese individuals. Aging Neuropsychol Cogn. 2013;20:684-99.

11. Stern Y. Cognitive reserve in ageing and Alzheimer's disease. Lancet Neurol. 2012;11:1006-12.

12. Chapko D, McCormack R, Black C, Staff R, Murray A. Life-course determinants of cognitive reserve (CR) in cognitive aging and dementia - a systematic literature review. Aging Ment Health. 2017;22:915-26.

13. Sobral M, Paúl C. Reserva cognitiva e doença de Alzheimer. Actas Gerontol. 2013;1:1-9. [accessed 2015 Jul 25]. Available from: https://www.academia.edu/27673784/Reserva_Cognitiva_e_ Doen\%C3\%A7a_de_Alzheimer.

14. De Wit L, Kirton J, O'Shea D, Szymkovicset S, McLaren M, Dotson V. Effects of body mass index and education on verbal and nonverbal memory. Neuropsychology Dev Cogn B Aging Neuropsychol Cogn. 2017;24:256-63.

15. Kirton J, Dotson V. The interactive effects of age, education, and BMI on cognitive functioning. Neuropsychology Dev Cogn B Aging Neuropsychol Cogn. 2016;23:253-62. without schooling and with or without comorbidities and emotional distress. They can offer better awareness of the risks, mechanisms and cognitive damages linked to obesity among which are neurodegenerative diseases.

\section{PROTECTION OF HUMANS AND ANIMALS}

The authors declare that the procedures followed were in accordance with the regulations established by the heads of the Commission for Clinical Research Ethics and in accordance with the Helsinki Declaration of the World Medical Association.

\section{DATA CONFIDENTIALITY}

The authors declare that they have followed the protocols of their work center on data publication.

\section{COMPETING INTERESTS}

The authors have declared that no competing interests exist.

\section{FUNDING SOURCES}

The authors have no funding to report.

16. Avramović P, Kenny B, Power E, McDonald S, Tate R, Hunt L. Exploring the relationship between cognition and functional verbal reasoning in adults with severe traumatic brain injury at six months post injury. Brain Inj. 2017;31:502-16.

17. Modica C, Bergsland N, Dwyer M, Ramasamy D, Carl E, Zivadinov R, et al. Cognitive reserve moderates the impact of subcortical gray matter atrophy on neuropsychological status in multiple sclerosis. Mult Scler. 2016;22:36-42.

18. Altieri M, Enzinger C, Trojano L, Santangelo G, Gallo A. Cognitive reserve and neuropsychological performance in multiple sclerosis: a meta-analysis. Neuropsychology. 2019. Neuropsychology. 2019;33:37990.

19. Hinrichs K, Easter R, Angers K, Pester B, Lai Z, Marshall D, et al. Influence of cognitive reserve on neuropsychological functioning in bipolar disorder: findings from a 5-year longitudinal study. Bipolar Disord. 2017;19:50-9.

20. Cserjési $R$, Luminet $O$, Poncelet $A$, Lénárd $L$. Altered executive function in obesity. Exploration of the role of affective states on cognitive abilities. Appetite. 2009;52:535-9.

21. Wanderley M, Hamdan A. Relações entre obesidade e controle inibitório: uma revisão sistemática. Rev Neuropsicol Latinoam. 2015;7:24-33.

22. Huet L, Delgado I, Aouizerate B, Castanon N, Capuron L. Obesity and depression: shared pathophysiology and translational implications. Neurobiology of Depression. 2019;169-83.

23. Olivo G, Gour S, Schiöth H. Low neuroticism and cognitive performance are differently associated to overweight and obesity: a cross-sectional and longitudinal UK Biobank study. Psychoneuroendocrinology. 2019;101:167-74.

24. Letra L, Santana I, Seiça R. Obesity as a risk factor for Alzheimer's disease: the role of adipocytokines. Metab Brain Dis. 2014,29:563-8.

25. Gaio V, Antunes L, Barreto M, Gil A, Kislaya I, Namorado S, et al. Prevalência de excesso de peso e de obesidade em Portugal: resultados do primeiro Inquérito Nacional de Saúde com Exame Físico (INSEF 2015). Obs Bol Epidemiol. 2018;22:29-33.

26. Appelhans B, French S, Pagoto S, Sherwood N. Managing temptation in obesity treatment: a neurobehavioral model of intervention strategies. Appetite. 2016;96:268-79.

27. Higgs S, Williamson A, Attwood A. Recall of recent lunch and its effect on subsequent snack intake. Physiol Behav. 2008;94:454-62.

28. Diamond A. Executive functions. Annu Rev Psychol. 2013;64:135-68.

29. Direcção-Geral de Saúde. Estratégia nacional para o envelhecimento ativo e saudável 2017-2025. Lisboa: DGS; 2017. [accessed 2019 Jun 
3]. Available from: https://www.sns.gov.pt/wp-content/uploads/2017/07/ ENEAS.pdf.

30. Tulsky D, Saklofske D, Chelune G, Heaton R, Ivnik R, Bornstein R, et al. Clinical Interpretation of the WAIS-III and WMS-III. Amsterdam: Academic Press; 2003.

31. Golden C, Espe-Pfeifer P, Wachsler-Felder J. Neuropsychological interpretation of objective psychological tests. New York: Springer; 2002.

32. Rey A. Teste de cópia de figuras complexas. $2^{a}$ ed. Lisboa: CEGOC; 1959

33. Cavaco S, Gonçalves A, Pinto C, Almeida E, Gomes F, Moreira I. et al Auditory verbal learning test in a large nonclinical portuguese population. Appl Neuropsychol Adult. 2015;22:321-31.

34. Fernandes S. (adapt). Stroop: teste de cores e palavras. Lisboa: CEGOC; 2013.

35. Cavaco S, Pinto C, Gonçalves A, Gomes F, Pereira A, Malaquias C Trail making test: dados normativos dos 21 aos 65 anos. Psychologica. 2008;49:222-38.

36. Heaton R, Chelune G, Talley J, Kay G, Curtiss G. Teste Wisconsin de classificação de cartas: manual revisado e ampliado. São Paulo: Casa do Psicólogo; 2005

37. Baptista AG. A génese da perturbação de pânico: a importância dos familiares e ambientais durante a infância e a adolescência. Tese de Doutoramento. Porto: Instituto de Ciências Biomédicas Abel Salazar; 1993.

38. Camolas J, Santos O, Mascarenhas M, Moreira P, Do Carmo I. Indivíduo: intervenção nutricional direcionada aos estilos de vida em indivíduos com obesidade. Acta Port Nutr. 2015;3:14-21.

39. Williams B, Mancia G, Spiering W, Rosei E, Azizi M, Burnier M, et al. 2018 ESC/ESH Guidelines for the management of arterial hypertension. Eur Heart J. 2018;39:3021-104.

40. Roldan-Tapia L, Garcia J, Canovas R, Leon I. Cognitive reserve, age, and their relation to attentional and executive functions. Appl Neuropsychol. 2012;19:2-8.

41. Lojo-Seoane C, Facal D, Juncos-Rabadán O, Pereiro A. El nivel de vocabulario como indicador de reserva cognitiva en la evaluación del deterioro cognitivo ligero. Anal. Psicol. 2014;30:1115-21.

42. Instituto Nacional de Estatística. Classificação portuguesa das profissões, 2010. Lisboa: INE; 2011.

43. Almeida VB. Características psicométricas do Wisconsin card sorting test em várias amostras da população portuguesa. Dissertação de Mestrado. Lisboa: Universidade Lusófona de Humanidades e Tecnologias; 2018.

44. Ribeiro O, Grencho D, do Carmo I, Paiva T, Figueira L, Góis H. Characterization of executive functioning in a Portuguese sample of candidates for bariatric surgery. Psychol Community Health. 2015;4:99113.

45. Gunstad J, Paul R, Cohen R. Obesity is associated with memory deficits in young and middle-aged adults. Eat Weight Disord. 2006;11:e15-9.

46. Oliveira A, Santos P. Hypertension: drug adherence and social factors. J Hypertens Manag. 2018;4.

47. Gaio V, Antunes L, Namorado S, Barreto M, Gil A, Kislaya I, et al. Prevalence of overweight and obesity in Portugal: results from the First Portuguese Health Examination Survey (INSEF 2015). Obes Res Clin Pract. 2017;12:40-50.

48. Mariano C, Antunes M, Rato Q, Bourbon M. e LIPID : caraterização do perfil lipídico da população portuguesa. Bol Epidemiológico - Inst Nac Saúde Dr Ricardo Jorge. 2015;4:7-10.

49. Browning L, Hsieh S, Ashwell M. A systematic review of waist-to-height ratio as a screening tool for the prediction of cardiovascular disease and diabetes: 05 could be a suitable global boundary value. Nutr Res Rev. 2010;23:247-69.

50. Ashwell M, Gunn P, Gibson S. Waist-to-height ratio is a better screening tool than waist circumference and BMI for adult cardiometabolic risk factors: systematic review and meta-analysis. Obes Rev. 2012;13:27586.

51. De Wit L, Kirton J, O'Shea D, Szymkowicz S, McLaren M, Dotson V.
Effects of body mass index and education on verbal and nonverbal memory. Aging, Neuropsychol Cogn. 2017;24:256-63.

52. Chao L, Knight R. Prefrontal deficits in attention and inhibitory control with aging. Cereb Cortex. 1997;7:63-9.

53. Tulving E. Episodic memory: from mind to brain. Annu Rev Psychol. 2002. 53:1-25.

54. Brunstrom J, Burn J, Sell N, Collingwood J, Rogers P, Wilkinson L, et al. Episodic memory and appetite regulation in humans. PLoS One. 2012;7.

55. Cheke LG, Simons JS, Clayton NS. Higher body mass index is associated with episodic memory deficits in young adults. Q J Exp Psychol. 2016;692305-23.

56. Elias M, Elias P, Sullivan L, Wolf P, D'Agostino R. Obesity, diabetes and cognitive deficit: The Framingham Heart Study. Neurobiol Aging. 2005;26:S11-6.

57. Lokken K, Boeka A, Yellumahanthi K, Wesley M, Clements R. Cognitive performance of morbidly obese patients seeking bariatric surgery. Am Surg. 2010;76:55-9.

58. Cohen J, Yates K, Duong M, Convit A. Obesity, orbitofrontal structure and function are associated with food choice: a cross-sectional study. BMJ Open. 2011;1:1-8.

59. Gameiro F, Perea M, Ladera V, Rosa B, García R. Executive functioning in obese individuals waiting for clinical treatment. Psicothema. 2017;29:61-6

60. Gayle A, Lee K, Boeka A, Lokken K. Neuropsychological performance of a clinical sample of extremely obese individuals. Arch Clin Neuropsychol. 2008;23:467-74

61. Raselli R, Bonfà F, Uber E, Marcheta L, Avanzi M, Baldini E, et al Exploratory evaluation of an obese population seeking bariatric surgery in an Italian public service. Eat Weight Disord - Stud Anorexia, Bulim Obes. 2013;15:e119-26.

62. Weinberger N, Kersting A, Riedel-Heller S, Luck-Sikorski C. The relationship between weight status and depressive symptoms in a population sample with obesity: the mediating role of appearance evaluation. Obes Facts. 2018;11:514-23.

63. Ginis K, McEwan D, Josse A, Phillips S. Body image change in obese and overweight women enrolled in a weight-loss intervention. The importance of perceived versus actual physical changes. Body Image. 2012;9:311-7.

64. Dimitriadis D, Mamplekou E, Dimitriadis P, Komessidou V, Dimitriadis G, Papageorgiou C. The association between obesity and symptoms of psychopathology and its relationship with sedentary behavior and mediterranean diet. Isr J Psychiatry Relat Sci. 2016;53:17-25.

65. Goodman DJ. Consumption as a global problem. In: Ritzer G, ed Handbook of social problems: a comparative international perspective. California: Sage; 2004. p. 226-45.

66. Social Care Institute for Excelence. Obesity and Mental Health, 2011. [accessed 2019 Jun 3]. Available from: https://www.scie-socialcareonline. org.uk/obesity-and-mental-health/r/a11G00000017trJIAQ.

67. Raman J, Smith E, Hay P, Gutierrez, Garcia E. The clinical obesity maintenance model: an integration of psychological constructs including mood, emotional regulation, disordered overeating, habitual cluster behaviours, health literacy and cognitive function. J Obes. 2013;2013:240128.

68. Santos I, Sniehotta F, Marques M, Carraça E, Teixeira P. Prevalence of personal weight control attempts in adults: a systematic review and meta-analysis. Obes Rev. 2017;18:32-50.

69. Campos J, Souza M, Araujo K, Olmo S, Lima A, Bergamini C. O impacto do peso flutuante sobre fatores de risco cardiovascular em mulheres obesas. HU Rev Juiz Fora. 2015;41:143-8.

70. Gunstad J, Paul R, Cohen R, Tate D, Spitznagel M, Gordon E. Elevated body mass index is associated with executive dysfunction in otherwise healthy adults. Compr Psychiatry. 2007;48:57-61.

71. Gunstad J, Lhotsky A, Wendell CR, Ferrucci L, Zonderman A. Longitudinal examination of obesity and cognitive function: results from the Baltimore longitudinal study of aging. Neuroepidemiology. 2010;34:222-9. 